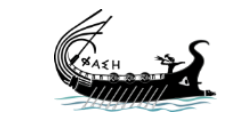

journal.phaselis.org

\title{
Phaselis 2016 Yılı Güney Limanı Amphora Buluntuları
}

\author{
South Harbor Amphoras of Phaselis Found in 2016
}

\section{Uğurcan ORHAN}

open 2 access journals

The entire contents of this journal, Phaselis: Journal of Interdisciplinary Mediterranean Studies, is open to users and it is an 'open access' journal. Users are able to read the full texts, to download, to copy, print and distribute without obtaining the permission of the editor and author(s). However, all references to the articles published in the e-journal Phaselis are to indicate through reference the source of the citation from this journal.

Phaselis: Journal of Interdisciplinary Mediterranean Studies is an international peerreviewed journal and the articles which have had their peer reviewing process completed will be published on the web-site (journal.phaselis.org) in the year of the journal's issue (e.g. Volume II: January-December 2016). At the end of December 2016 the year's issue is completed and Volume III: January-December 2017 will begin.

Responsibility for the articles published in this journal remains with the authors.

Citation U. Orhan, "Phaselis 2016 Yılı Güney Limanı Amphora Buluntuları". Phaselis III (2017) 141148 DOI: $10.18367 /$ Pha.17008

Received Date: 25.04.2017 | Acceptance Date: 22.06.2017 | Online Publication Date: 13.07.2017

Editing Phaselis Research Project www.phaselis.org 


\title{
Phaselis 2016 Yılı Güney Limanı Amphora Buluntuları
}

\author{
South Harbor Amphoras of Phaselis Found in 2016
}

\author{
Uğurcan ORHAN*
}

Öz: Phaselis Güney Limanı mendireğinin çevresinde 2016 yılında sualtı araştırmaları gerçekleştirilmiştir. Mendireğin içerisinde ve dışında farklı üretim merkezlerine ait amphora parçaları tespit edilmiştir. Sualtı araştırmasında farklı tipteki ticari amphoralara rastlanılması bölgedeki ticaret trafiğini göstermesi açısından önemlidir. Bu makalenin amacı, dalışlar sırasında bulunan amphoraları sınıflandırmak, tarihlendirmek ve kentin ticari ilişkisini tespit etmektir. Amphoralar, depozit ya da kontekst buluntuları olmadıkları için, benzer örneklerden yola çıkılarak tarihlenmiştir. Güney Limanı'nda saptanan amphoraların ilk kez çalışılması ve limanın kullanım evrelerinin belirlenmesinde amphoraların tarihlerinin kriter olarak ele alınacak olması makalenin önemini teşkil etmektedir. Bulunan amphoralar tipolojik olarak sınıflandırılı̆̆ında 6 farklı form tespit edilmiştir. Bu formlar Kuzey Afrika amphoraları, Mısır amphoraları, Doğu Akdeniz amphoraları, Kilikia Bölgesi amphoraları, Ege Bölgesi amphoraları olmak üzere 5 başıkta toplanmıştır. MS III. yüzyıldan MS VII. yüzyıla kadar bölgede ticaretin yapıldığını işaret etmektedir. Doğu Akdeniz kökenli amphoraların yoğunlukta olduğu görülmektedir. Bu yoğunluk Phaselis'in Doğu Akdeniz'de bulunan merkezler ile ticari faaliyetlerini karşımıza çıkarmaktadır.

Anahtar Sözcükler: Phaselis, Güney Liman, Sualtı Araştırması, Ticari Amphora, Ticari Faaliyetler

Abstract: Underwater research was carried out around jetty in 2016. Amphora pieces belonging to different production centers inside and outside of the jetty were identified. The found of different types of commercial amphoras in underwater research is important to show trade traffic in the region. The purpose of this article is to classify and date the amphoras which found during the diving to determine the city's commercial relationship. Amphoras do not have a deposit or context so it is dated based on similar examples. The first study of amphoras in the South Port and the determination of the use phases of the harbor are important in that the dates of amphoras will be taken as criteria. When amphoras were classified typologically, 6 different forms were determined. These forms were collected in 5 titles which is North African amphoras, Egyptian amphoras, Eastern Mediterranean amphoras, Cilicia Amphoras, Aegean Amphoras. It indicates that trade was carried out in the region from the III. century A.D. to the VII. century A.D. It is seen that the amphoras of Eastern Mediterranean origin are intensified. This intensity indicates the commercial activities of Phaselis with the centers located in the Eastern Mediterranean.

Keywords: Phaselis, South Harbor, Underwater Research, Transport Amphorae, Commercial Activity

Günümüz Antalya İli, Tekirova İlçesi sınırları içerisinde bulunan ve Pamphylia Körfezi'nin batı sahilinde yer alan Phaselis kenti Güney Liman mendireği çevresinde 2016 yılında sualtı araştırmaları yapılmıştır. Bu araştırmalar Güney Liman Mendireğin çevresinde 10 ile 18 metre arası değişen derinliklerde yapılmıştır. Araştırmalarda Güney Liman mendireği çevresinde 6 farklı amphora formu tespit edilmiştir (Fig. 1). Tespit edilen ticari amphoraların bir bölümü boyun ve

*M.A., Selçuk Üniversitesi, Sosyal Bilimler Enstitüsü, Arkeoloji Bölümü, Konya. orhanugurcan@gmail.com 
kulptan, bir bölümü ise tama yakın formdan oluşmaktadır. Söz konusu amphoralar üretim yerlerine göre sınıflandırıldığında, Kuzey Afrika (1 form), Mısır (2 form), Doğu Akdeniz (1 form), Kilikia Bölgesi ( 1 form) ve Ege Bölgesi ( 1 form) kökenli olmak üzere 5 farklı bölgeden geldiği tespit edilmiştir. Araştırmanın izni ve kapsamı gereği tespit edilen amphoralar yerinde belgelendiği için kil ve toprak analizi yapılma imkânı bulunmadığından çalışmamızda bu formlar salt formlarına göre benzerleri ile karşılaştırımış, bölgelerine göre ayrılmış, tanıtılmış ve tarihlendirilmiştir.

\section{Tripolitania Bölgesi}

\section{Tripolitania Tip 1 Amphorası}

Phaselis Güney Liman mendireğinin güney tarafında bulunan Tripolitania amphorası, Yaklaşık 10 metre derinlikte, nispeten sığlık bir alanda tespit edilmiştir.

Tripolitania tip 1 Amphorası, Ostia LXIV, Bengazi ERA 11a gibi isimler ile de anılmakta olup, yüzey araştırmalarında ve kil analizleri üzerine yapılan çalışmalarda bu amphoranın Kuzey

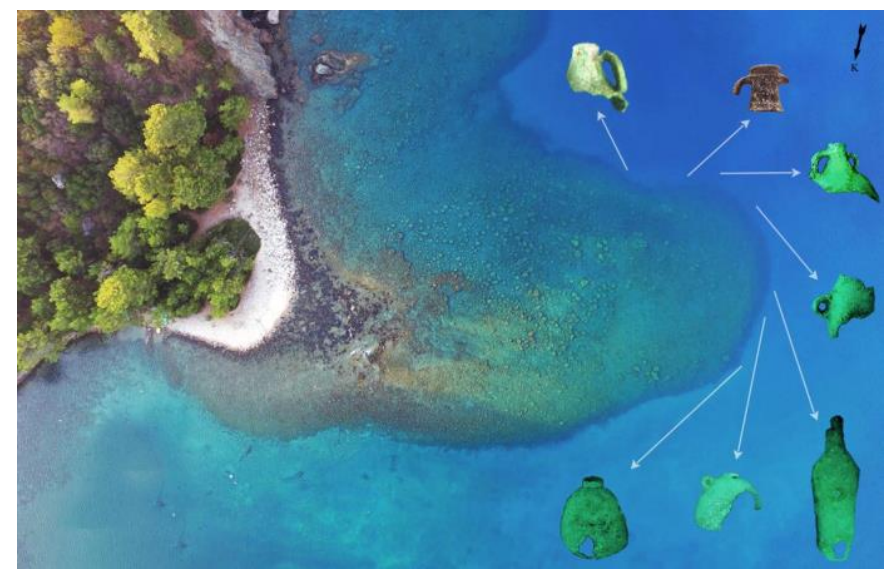

Fig. 1. Güney Liman Mendireği Çevresi Amphora Dağılımı Afrika'da Tripolitania'da üretilmiş oldukları tespit edilmiştir ${ }^{1}$. Tripolitania tip 1 amphorası üzerinde yapılan analizler ve Kuzey Afrika'nın önemli ihraç malzemesinin zeytinyağı olması göz önüne alındığında bu tip amphoraların zeytinyağı taşıyor olabileceği düşünülmektedir².

Çalışmamızda yer alan Tripolitania tip 1 amphorası, ağızın bir bölümü, boynun bir kısmı ve tek bir kulp sağlamdır ve yoğun kalker tabakası ile kaplıdır. Bu amphora form olarak ise, dışa çekik, üçgen profilli ve bant formunda ağız kenarına, kısa silindirik bir boyuna, boynun üst bölümü ile omzun üst bölümü arasında yuvarlak kesitli kısa kulplara sahiptir. Bu formun sağlam örneklerinde ise ovoidal, kaideye doğru daralan gövdeye ve içi dolu kısa sivri bir kaideye sahiptir.

Tripolitania tip 1 için benzerleri ile karşılaştıııldığında, Berenike'de Augustus dönemiª, Ostia'da MS II. yüzyıl başı ve MS III. yüzyıl başına, Paphos'da MS II. yüzyıl başına, Caesarea'da MS IV. yüzyıl başına4, Kekova Adası Kuzey Yerleşim alanı, sualtında tespit edilen Tripolitania tip 1 amphorası MS I. ve III. yüzyıl arasına tarihlenmiştir ${ }^{5}$. Benzer örneklerden yola çıkarsak, Phaselis Güney Liman Mendireği çevresinde tespit edilen bu amphora için MS III. ve IV. yüzyıl aralığı önerilmektedir (Fig. 2).

\section{Mısır Bölgesi}

\section{AE 5-6 Tipi Amphora}

AE 5-6 amphorası, Phaselis Güney Limanı mendireğinin güney ucunda 12 ile 16 metre arası değişen

\footnotetext{
1 Şenol 2000, 213.

2 Keay $1984,130-132$.

3 Riley 1979, 166-167.

4 Şenol 2000, 205.

5 Aslan 2015, 354, kat. 15.
} 
derinliklerde tespit edilmiştir.

Kartaca LR-5-6, Peacock-Williams 46, Riley LR 4, Egloff 187 gibi isimler ile de anılmış olup, daha doğru bir isimlendirme olan Mısır Tip 5 (AE 5-6) ismi önerilmektedir6.

İskenderiye'nin güneyinde, Mareotis Gölü kıyısındaki atölyelerde, bu tipin benzerleri üretilmiş olup, aynı zamanda Mareotis dışında Abou Mena'da da yoğun olarak üretilmiştir7. Mısır'da bulunan pek çok AE 5-6 amphorasının, kentin son derece önemli ihraç ürünü olan şarabın taşınmasında kullanıldığı düşü-

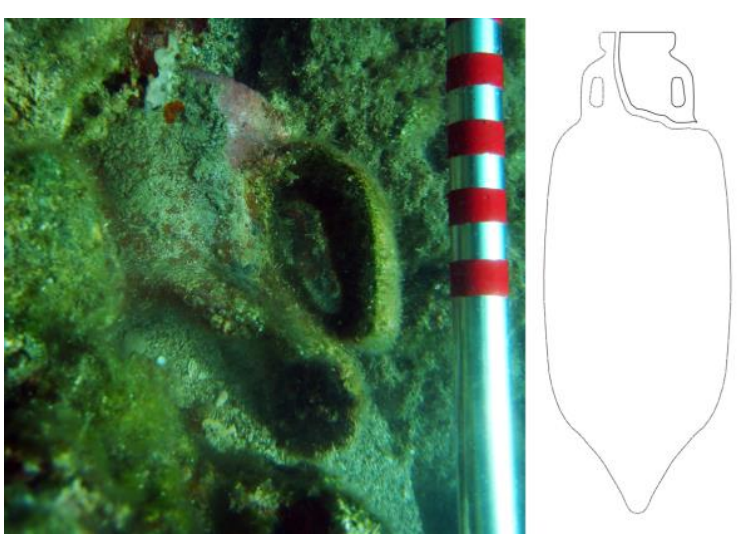

Fig. 2. Tripolitania Tip 1 Amphorası nülmektedir. Ain El-Jedide'de MS VI. yüzyıla ve El-Kurside'de MS VII. ve VIII. yüzyıla tarihlenen şarap preslerinin bulunması da kentin ihracatında şarabın rolünü ortaya çıkarmakta ve aynı zamanda AE 5-6 amphoralarının şarap taşıdığı görüşünü desteklemektedir8.

Çalışmamızda, AE 5-6 tipi iki adet amphora tespit edilmiş, biri nispeten sağlam, gövde üzerinde dibe yakın bir noktada kırık mevcut iken diğer AE 5-6 amphorasının üzeri yoğun kalker tabakası ile kaplı şekilde sadece ağız ve kulp günümüze kadar ulaşabilmiştir. Bu iki adet (Fig. 3-4) AE 5-6 amphorası form olarak, dışa çekik ucu yuvarlatılmış yüksek ağız kenarı, gövdeye doğru genişleyen konik formlu omuzları, omuzun üzerinde yivli yuvarlak kesitli dikey kulplar ve üzerinde ince yivler bulunan torba formlu, gövdesi ve dibi yuvarlak bir forma sahiptir.

AE 5-6 amphorasının benzerleri, Marmaris Müzesi9, Arslan Eyce Taşucu Amphora Müzesi10, Bodrum ${ }^{11}$, Dolikhiste Kuzey Yerleşim Limanı12, Kekova Adası Kuzey Yerleşim Alanı'nda ${ }^{13}$ görülmektedir.

Phaselis Güney Limanı mendireğinin güney ucunda tespit edilen bu amphora için ise benzerlerinden yola çıkılarak MS VI. ve VII. yüzyıllar aralığı önerilmektedir14 .

\section{AE 3 Tipi Amphora}

AE 3 Amphorası, Phaselis Güney Limanı mendireğinin güney ucunda 10 ile 15 metre arası değişen derinliklerde tespit edilmiştir.

İskenderiye'nin güneyinde, Mareotis Gölü kıyısındaki atölyelerde yoğun olarak üretim görmüş, MS I. yüzyıla tarihlenen örnekler Sicilya'da bulunan batıklarda, MS I. yüzyıl sonlarında ise Fos A Batığı'nda rastlanılmıştır15. MS II. ve III. yüzyıllar da Kıbrıs'ta Nea Paphos kentinde yapılan kazılarda yoğun şekilde AE 3 amphoralarına rastlanılmakta, bu tarihlerden itibaren Akdeniz'in doğusundan Caesarea Maritime'e de, MS V. yüzyıla kadar ticaretinin yapıldığı düşü-

\footnotetext{
6 Şenol 2000, 255.

7 Şenol 2009, 273.

8 Zemer 1977, 69-70.

9 Şenol 2003, 125-127.

10 Şenol 2009, 272-274.

11 Alpözen v.d 1995, 65.

12 Aslan 2011, 112-113.

13 Aslan 2015, 359.

14 Şenol 2000, 346.

15 Şenol 2000, 250.
} 
nülmektedir16.

Ayrıca İstanbul ve çevresindeki kazılarda az miktarda da olsa AE 3 amphoralarına rastlanılmış olup bu formun MS VIII. yüzyıla kadar kullanıldığı düşünülmektedir ${ }^{17}$.

Üretim yerleri ve çağdaşları ile karşılaştırıldığı zaman önemli bir ihraç ürünü olan şarabın taşındığı görüşü savunulmakta olup Mısır kökenli amphoralar olduğu düşünülmektedir18.
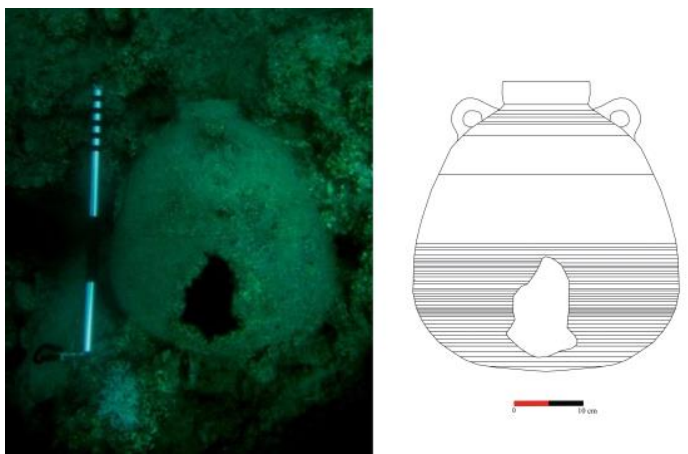

Fig. 3. AE 5-6 Tipi Amphora
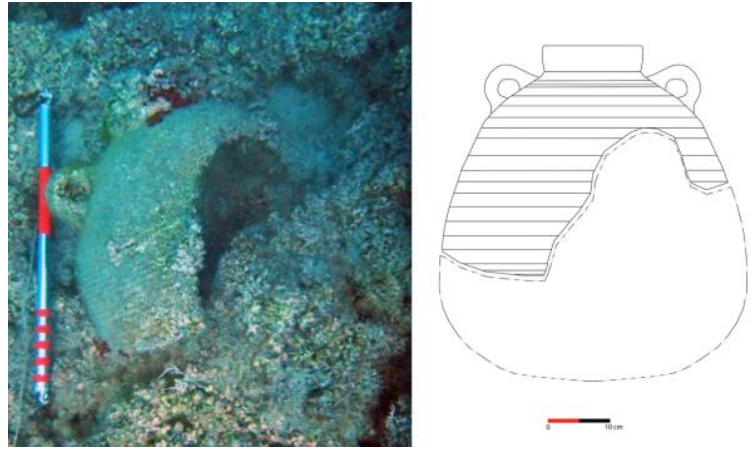

Fig. 4. AE 5-6 Tipi Amphora

Çalışmamızda yer alan AE 3 tipi amphora, ağız, kulp ve gövde günümüze kadar korunarak gelmiş olup, gövde üzerinde dibe yakın bir noktada $0.12 \times 0.8 \mathrm{~m}$ ölçülerindeki kırık tespit edilmiştir. Bu amphora form olarak, ucu yuvarlatılmış dışa çekik yuvarlatılmış üçgen formlu ağız kenarı, içinde ve dışında kalın yivler bulunan ince uzun silindir şeklinde boyna ve ağız kenarı seviyesinde boyunla birleşen oval kesitli kulplara sahiptir. AE 3 amphorasının benzerleri, Arslan Eyce Taşucu Amphora Müzesi'nde ${ }^{19}$ bulunmakta olup, çalışmamızda tespit edilmiş olan AE 3 amphorası için ise tarih olarak MS III. yüzyıl önerilmektedir20 (Fig. 5).

\section{Doğu Akdeniz Amphoraları}

\section{LR 4 B-1 Tipi Amphora}

LR 4 amphorası, Phaselis Güney Limanda Mendireği güneyinde Yaklaşık 15 metre derinlikte tespit edilmiştir.

Almagro 54, Kuzmanov XIV ve Cartaga LR 4 amphorası olaraktan pek çok kaynakta karşımıza çıkmaktadır21. İsrail kıyılarında Caesarea Hipodromu'nda yapılan kazılarda ortaya çıkarılan LR-4 tipi amphoraların kil analizleri sonucunda Gaza Bölgesi'nde üretilmiş olduğu düşünülmektedir22.

LR 4 amphoralarında Gaza Şarabı taşındığı görüşü savunulmakta olup23, MS V. ve VI. yüzyılda yaşamış yazarlar, Gaza şarabından övgü ile bahsetmiş olmaları24 ise bu görüşü kanıtlar niteliktedir.

Çalışmamızda tespit edilen LR-4 amphorası, ağız ve kulplar sağlam kalmış olup, gövde ise iki kulp hizasında kırılmış şekilde günümüze kadar ulaşmıştır. Bu amphora form olarak ise, ucu

16 Şenol 2000, 250-251.

17 Riley 1975, 31.

18 Şenol 2000, 250.

19 Şenol 2009, 269.

20 Şenol 2000, 486-487.

21 Peacock-Williams 1986, 198.

22 Riley 1975, 30.

23 Mayerson 1985, 76-78.

24 Riley 1975, 30. 
yuvarlatılmış dışa doğru çekilmiş ağız kenarı, çok kısa boyuna, omuz üzerinden başlayan ve gövdeyle birleşen ince oval kesitli oval formda kısa kulplara sahiptir.

Benzer örneklere bakılarak ise uzun silindirik bir gövdeye sahip olduğu anlaşılmaktadır. Ayrıca kulpların altından başlayarak kaideye doğru inen yivler bulunmaktadır. Bu form özellikleri dikkate alındığında LR 4 amphorası B1 tipi olarak anılan sınıfa girdiği düşünülmektedir25. Bu formun benzerleri, Arslan Eyce Taşucu Amphora Müzesi'nde MS V. ve VI. yüzyıl arasına26, İçel Müzesi'nde MS VI. ve VII. yüzyıl arasına27, Silifke Müzesi'nde MS VI. yüzyıla28, Kekova Adası Kuzey Yerleşim alanı'nda bulunan bir başka benzeri ise MS VI. ve VII. yüzyıl aralı̆ıına tarihlendirilmektedir29.

Çalışmamızda Phaselis Güney Liman mendireğinde

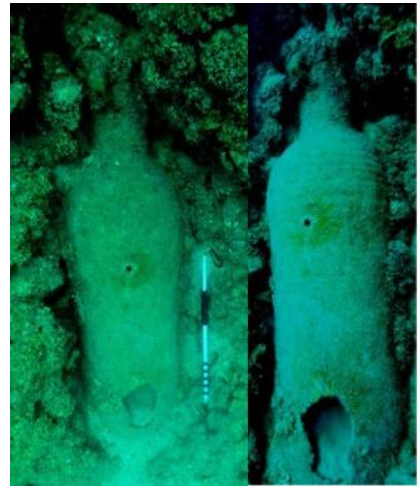

Fig. 5. AE 3 Tipi Amphora tespit edilen LR 4 B1 tipi amphora için ise MS VI. yüzyıl tarihi önerilmektedir (Fig. 6).

\section{Kilikia Bölgesi}

\section{LR 1 B Tipi Amphora}

LR 1 B amphorası, Phaselis Güney Limanı mendireği güneyinde, yaklaşık 15 metre derinlikte tespit edilmiştir.

LR 1 amphorası, Ballana 6, Kuzmanov XIII, Scorpan 8B, Kartaca LR 1, Benghazi LR 1, Keay LIII ${ }^{30}$ ve Augst 58, Thomas Bii, Egloff 164-167, Keay 18, Peacock Form 2, Peacock Williams 44, Sabratha Tip 27 gibi isimler ile de anılmaktadır31. Bu amphoralar, Kilikia Bölgesi'nde yapılan çalışmalarda bazı üretim atölyelerine rastlanılmıştır32. Kıbrıs'ta gerçekleştirilen yüzey araştırmalarında ise bu iki bölgede üretildikleri fikri kesinleşmiş olup, Kilikia Bölgesi'nde Elaiussa Sebaste

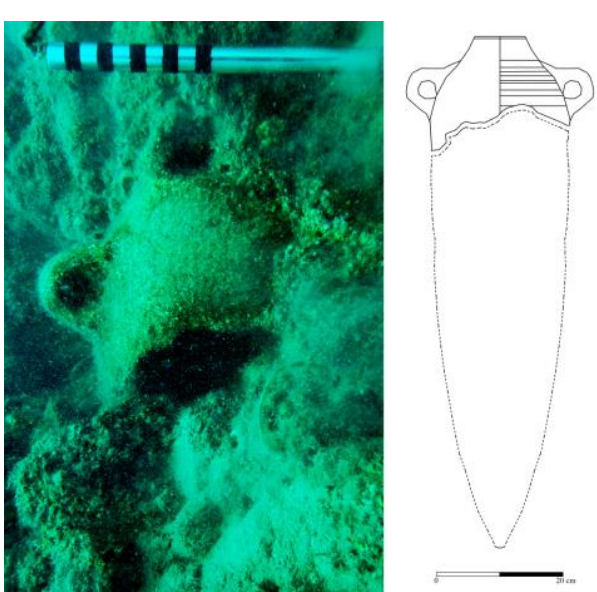

Fig. 6. LR 4 B-1 Tipi Amphora ile Seleukeia Pieria sınırları arasında kalan alanda ve Yumurtalık Körfezi etrafında LR 1 amphoralarının üretilmiş olduğunu kesinleştiren atık seramik tabakaları belirlenmiştir ${ }^{33}$. Bu amphoraların, Kilikia Bölgesi ve Kıbrıs dışında birçok bölgede üretim atölyelerinin olduğu saptanmıştır. Farkı tarihlerde Rhodos, İçmeler, Tarsus, Magarsos, Aigia, Antiokheia, Kourion, Amathous gibi birbirinden ayrı yerlerde üretim atölyelerine rastlanılmıştı ${ }^{34}$.

LR 1 amphoraları ile taşınan malzemeler hakkında ise birden fazla görüş ortaya atılmaktadır.

\footnotetext{
25 Pieri 2007, fig. 8.

26 Şenol 2009, 259, kat. 97.

27 Şenol-Kerem 2000, 92.

28 Alkaç 2013, 116, fig. 11.

${ }^{29}$ Aslan 2015, 357, kat. 26.

30 Peacock-Williams 1986, 185.

31 Şenol 2000, 196.

32 Empereur-Picon 1989, 236-239, fig. 18-19.

33 Şenol 2009, 145.

34 Empereur-Picon 1989, 236-239, fig. 18-19.
} 
Bu görüşlerden biri zeytinyağı ticareti yapıldığı görüşüdür35. MS IV. ve VI. yüzyıllar arasında, Antiokhia civarında üretimi yapılan zeytinyağı ile aynı tarihlerde paralellik gösteren amphora üretimi, zeytinyağının taşınmış olabileceği görüşünü desteklemektedir' ${ }^{36}$. Öte yandan Yassıada Batığı'nda bulunan LR 1 amphoraların içinden üzüm çekirdeklerinin çıkması MS VII. yüzyıl'da LR 1 amphoralarının şarap ticareti için de kullanıldıklarını kanıtlamıştır ${ }^{37}$.

Phaselis Güney Limanı mendireğinin güneyinde tespit ettiğimiz LR 1B tipi amphora, ağız, boynun bir kısmı ile kulpları günümüze kadar ulaşabilmiş̧ir. Bu amphora form olarak, dışa taşkın yuvarlatılmış ağız kenarı sahiptir. Benzer örneklere bakıldığında, dudağın hemen altından başlayan ve omuzda gövdeyle birleşen oval kesitli yivli kulplara sahip olup, gövdenin en geniş yeri omuzdadır ve ovoid gövde yapısına sahiptir, küçük bir çıkıntıya sahip dip yapısı sivrilerek sona ermekte ve kulpların altından kaideye kadar dış yüzeyde sık yivler bulunmaktadır.

LR 1-B amphorası için benzer örneklerden yola
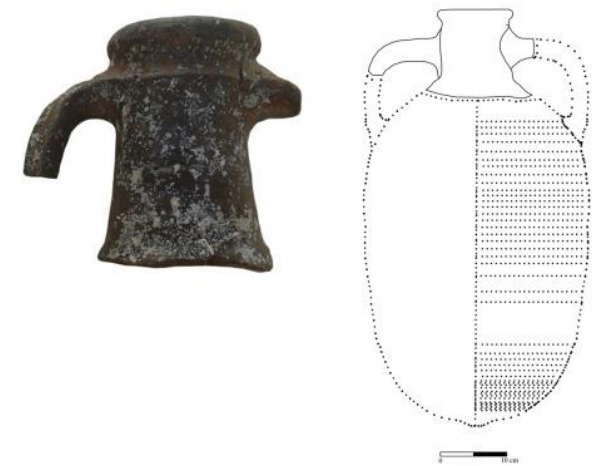

Fig. 7. LR 1-B tipi amphora çıkarak, Marmaris Müzesi'nde MS V. yüzyılın ilk yarısı38, Arslan Eyce Taşucu Amphora Müzesi'nde MS V. ve VI. yüzyıl aralığ| ${ }^{39}$, Silifke Müzesi'nde MS VI. ve VII. yüzyıl aralığı40, Kekova Adası Karaöz Mevki'nde tespit edilen LR 1-B amphorası ise MS VI. ve VII. yüzyı|41 olarak tarihlenmiştir. Çalışmamızda yer alan LR 1-B amphorası için ise MS VI. ve VII. yüzyıl aralığı önerilmektedir (Fig. 7).

\section{Ege Bölgesi}

\section{LR 2 C Tipi Amphora}

LR 2 C amphorası, Phaselis Güney Liman mendireği'nin güney kısmında, yaklaşık 15 metre derinlikte tespit edilmiştir.

LR 2 C amphorası; British Bi, Kuzmanov XIX, Scorpan 7A, Kartaca LR amphora 2, Benghazi LR amphora 2, Keay LXV42 ve Beltran 71, Keay XXI, Sabratha Tip $25^{43}$ olarakta anılmaktadır. LR 2 amphoralarının üretim yeri olarak Ege ve Karadeniz bölgeleri önerilmiş ${ }^{44}$, yapılan kil analizleri ise Kuzey Ege'de ve Halikarnassos civarında da üretilmiş olabileceği düşünülmektedir45. Kesin olmayan bu üretim yeri önerilerini ise Khios'da ve Romanya'da bulunmuş olan atölyeler kanıtlamıştır ${ }^{46}$. LR 2 C amphoraları üzerinde yapılan analiz çalışmalarında, çam sakızı, mersin reçinesi ve terebentinin az miktarda7, yoğunlukla zeytinyağı ve şarabın taşındığı düşünülmektedir48.

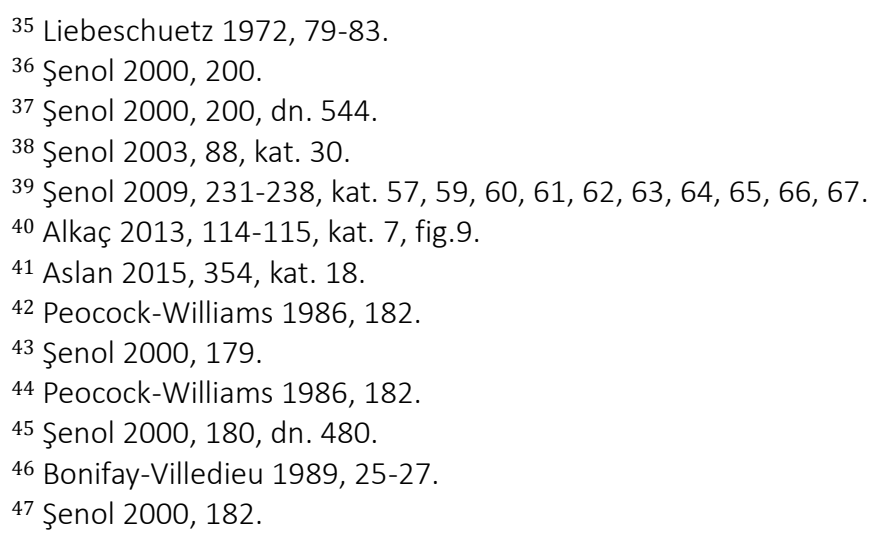


Çalışmamızda tespit edilen LR 2 C tipi amphoranın ağız ve kulbu korunmuş, gövde kırık şekilde tespit edilmiştir. Yoğun kalker tabakasından dolayı ise birçok ayrıntı görülememektedir. Bu amphora form olarak, dışta keskin üçgen halka formlu ucu yuvarlatılmış yüksek ağız kenarına, boyunun ortasından omuzla birleşen yuvarlak kesitli kalın kulplara, yüksek konik bir boyuna, alt kısma doğru daralan yuvarlatılmış küresel bir gövdeye sahiptir. LR 2 amphoraların üçüncü alt grubu olan LR 2C amphoraları LR 2C amphorası diğer formlar ile yakın benzerlik göstermesine karşılık daha kalın bir boyun ve kulpların omuzlara oturma açısındaki farklılık daha gelişmiş bir versiyonu olarak düşünülmektedir49.

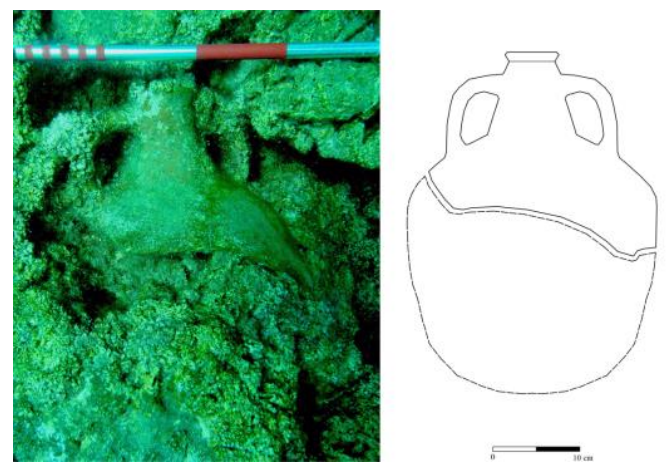

Fig. 8. LR-2C tipi amphora

Benzer örnekleri ile karşılaştıııldığında Kartacada MS VI. yüzyıl50, Tomis ve Marmaris Müzesi'nde MS IV. ve VI. yüzyılaralığ|51, Arslan Eyce Taşucu Amphora Müzesi'nde MS VII. yüzyı ${ }^{52}$, Kekova Adası Kuzey Yerleşim Alanı'nda tespit edilen LR 2 C amphorası için ise MS VII. yüzyıl tarihi önerilmektedir53. Phaselis Güney Liman Mendireği güney ucunda tespit edilen LR $2 C$ tipi amphora için ise MS VI. yüzyıl sonu VII. yüzyıl başları önerilmektedir ${ }^{54}$ (Fig. 8).

\section{Değerlendirme}

Phaselis kentinin ticari ve sosyal hayatında büyük bir önemi olduğunu düşündüğümüz Güney Liman, yüzyıllar boyunca Phaselis'in dış dünya ve Akdeniz ile bağlantısını sağlamış olmalıdır. 2016 yılı çalışmalarında tespit edilerek yukarda detayları ile tanıtılmış olan 7 amphoranın, ilerleyen yıllardaki çalışmalar ile sayısının artacağı kuşkusuzdur. Eldeki bu ilk verilerle Güney Liman mendireği çevresinde yapılan dalışlarda saptanan amphoralar, Phasalis'in deniz ticaretinde, MS III. ve IV. yüzyıl aralığında Kuzey Afrika ile Tripolitania tip 1 amphorası, Mısır ile MS VI. ve VII. yüzyıl aralığında AE 5-6 amphorası iken AE-3 tipi amphora ile MS III. yüzyıl dolaylarında, MS VI. yüzyıl'da Doğu Akdeniz ile LR 4 B1 tipi amphora, MS VI. ve VII. yüzyıl aralığında Kilikia Bölgesi ile LR-1B tipi amphora ve MS VI. yüzyıl sonu VII. yüzyıl başlarında ise Ege Bölgesi'nden LR 2C tipi amphora vasıtası ile ticari bağlantılar kurduğu ortaya konmaktadır. Amphoralarda, zeytinyağı, şarap, çam sakızı, mersin reçinesi ve terebentin taşınmakta olduğu düşünülmektedir. Öte yandan Phaselis Güney Liman'ın içi, gerek akarsuların taşıdığı alüvyon, gerekse dalganın biriktirdiği kumların etkisiyle dolduğu, dip hareketleri sayesinde ise önümüzdeki yıllarda yapılacak çalışmalarda daha farklı tip ve formda amphora ile karşılaşılacaktır.

\footnotetext{
48 Şenol 2009, 149-150.

49 Şenol 2000, 179.

50 Peocock-Williams 1986, 183-184.

51 Şenol 2003, 97-98.

52 Şenol 2009, 248, kat. 83.

53 Aslan 2015, 355-356, kat. 22.

54 Peocock-Williams 1986, 184.
} 


\section{BíBLIYOGRAFYA}

Alkaç 2013

Alpözen v.d 1995

Aslan 2011

Aslan 2015

Bonifay-Villedieu 1989

Empereur-Picon 1989

Keay 1984

Liebeschuetz 1972

Mayerson 1985

Peacock-Williams 1986

Pieri 2007

Riley 1975

Riley 1979

Şenol-Kerem 2000

Şenol 2000

Şenol 2003

Şenol 2009

Zemer 1977
E. Alkaç, "Silifke Müzesinde Doğu Akdeniz Üretimi Amphoralar". Cedrus I (2013) 107-124.

T. O. Alpözen - A. H. Özdaş - B. Berkaya, Bodrum Sualtı Arkeoloji Müzesi Ticari Amphoraları. Ankara 1995.

E. Aslan, Kekova Bölgesi Limanları. Doktora Tezi, Selçuk Üniversitesi. Konya 2011.

E. Aslan, "Kekova Adası 2012-2013 Yılı Sualtı Araştırmalarında Bulunan Amphoraların Tipolojik Değerlendirmesi". Olba XXIII (2015) 321-369.

M. Bonifay - F. Villedieu, "Importation d'amphores orientales en Gaule". Eds. V. Déroche, J. M. Spieser BCH XVIII (1989) 17-46.

J. Y. Empereur - M. Picon, "Les régions de production d'amphores impériales en Méditerranée Orientale". Amphores Romanes Storia Economica: Un Decenio Di Richerce, Collection De L'Ecole Française De Rome (1989) 114, 223-248.

S. J. Keay, "Late Roman Amphorae in the Western Mediterranean: a typology and economic study". The Catalan Evidence, BAR IntSer 196(i), Oxford.

J. H. W. G. Liebeschuetz, Antioch: City and Imperial Administration in the Later Roman Empire. Oxford 1972.

P. Mayerson, "The Vine and Vineyards of Gaza in the Byzantine Period". BASOR 257 (1985) 75-78.

D. P. S. Peacock - D. F. Williams, Amphorae and the Roman Economy: An Introductory Guard. London 1986.

D. Pieri, "Les Centres de Production d'Amphores en Mediterranée Orientale Durant L'antiquité Tardice: Quelques Remarques". Eds. M. Bonifay - J. C. Treglia, late Roman Coarse Wares, Cooking, Wares and Amphorae in the Mediterranean: Archaeology and Archaeometry 2, Marseille and Arles, 13-16 April 2015, BAR IntSer 1162. Oxford (2007) 611- 625.

J. A. Riley, "The Pottery from the First Session of Excavation in the Caesarea Hippodrome". BASOR 218 (1975) 25-63.

J. A. Riley, "The coarse pottery from benghazi, Excavations at sidi Khrebish, Benghazi (Berenice)". Eds. J. A. Lloyd, Suppl. to Libya Antiqua V/II, Tripoli (1979) 91-497.

A. K. Şenol - F. Kerem, "İçel Müzesinde Bulunan Bir Grup Amphora". Olba III (2000) 81-114.

A. K. Şenol, Iskenderiye Kazılarında Ele Geçen Amphoralar Işığında Kentin Roma Dönemi Şarap, Zeytinyağı, Salamura Balık ve Sosyal Ticareti. Yayınlanmamış Doktora Tezi, Ege Üniversitesi. İzmir 2000.

A. K. Şenol, Marmaris Müzesi Ticari Amphoraları. Ankara 2003.

A. K. Şenol, AETAM (Arslan Eyce Taşucu Amphora Müzesi)'da Bulunan Ticari Amphoralar ve Akdeniz'de Ticaretin Izleri. Mersin 2009.

A. Zemer, Storage Jars in Ancient Sea Trade. Haifa 1977. 